\title{
EFFECT OF EARLY AND LATE CASTRATION ON ODOR GLANDS AND SKIN CHARACTERISTICS IN MALE BALADI GOATS \\ Abdel-Moneim, A.Y.* and Kh. M. Mazher ${ }^{* *}$ \\ * Dept. Animal Production, Fac. Agric., Cairo Univ., Giza- Egypt \\ ** Dept. Cytology and Histology, Fac. Veterinary Medicine, Beni-Suef \\ Univ., Beni-Suef , Egypt
}

\begin{abstract}
Skin samples of five body regions (parietal, shoulder, mid-side, coxal tuber and perianal ) were collected from nine male Baladi goats aged 16 months. The influences of body region and age of castration (early 2-week versus late 6- month of age ) on odor glands, hair follicles and epidermis were examined and tested. Skin from parietal region of kids exhibited significantly $(P<0.05)$ the highest density of follicles $(55.8 /$ $\mathrm{mm}^{2}$ ), among the other body regions. Whereas, parietal (1.7) and shoulder (1.5) regions were lower in S/P ratio than mid-side, coxal tuber (2.5 for each) and perianal $(3, P<0.05)$ regions. Body region had a highly significant $(P<0.01)$ effect on density of sweat glands and sebaceous glands. The highest density of sweat glands was found in parietal region $\left(14.8 / \mathrm{mm}^{2}\right)$. Though the density of sebaceous glands in parietal region $\left(26.0 / \mathrm{mm}^{2}\right)$ ranked the second after perianal region $\left(36.6 / \mathrm{mm}^{2}\right)$, their size was larger in parietal region than in other body regions. Two-week castrated kids had significantly $(P<0.05)$ less density of sweat glands than entire kids. However, the difference between entire kids and 6 - month castrates in sweat glands density was insignificant $(P>0.05)$. As well, 2-week castrated kids had the lowest density of sebaceous glands compared with entire kids and 6 - month castrated ones. Histologically, the parietal glands of entire kids appeared highly modified and larger occupying the major part of the dermis with marked secretory activity than other regions as well as castrated kids. Sweat and sebaceous glands in parietal region of Baladi bucks are the major source of buck odor. Furthermore, the attained results revealed that castration of kids at an early age of life (2-weeks of age) plays an important role in reducing male odor.
\end{abstract}

Keywords: Baladi kids, castration, body region, skin follicles, skin glands

\section{INTRODUCTION}

In Egypt, goats represent an economically and promising source of red meat, consequently, they are broadly spread allover the country. However, buck odor is inconvenient in goat herds because it can permeate a wide array of substances in the immediate environment, including slaughtered entire kids and milk, with a negative impact on dairy product quality. Many researches have been done to study the effect of castration of entire kids on odor of goat milk and meat, but very few investigations have been oriented to determine the best time of castration and its effect on milk, meat and mainly on odor glands and skin characteristics. The problem of buck odor was discussed by many researchers who were not in agreement concerning the part of the body that is actually responsible of this odor. Some of them indicated that the source of buck odor (pheromones) may be originated from skin and/or urine. However, Jenkinson et al. (1967) confirmed that urine does not contribute in any way to the appearance of buck odor. 
The main aim of this research was to study the effect of age at castration (early versus late) on odor glands and skin characteristics in male Baladi goats.

\section{MATERIALS AND METHODS}

\section{A. Animals and management:}

Nine male Baladi kids born in the goat farm of Faculty of Agriculture, Cairo University, Egypt were used in the present study. Kids were randomly classified into three equal groups i.e. 1) entire kids, 2) kids castrated at 2 weeks of age and 3) kids castrated at 6 months of age. Castration was practiced using a silk string tied strongly around the neck of the testes at their connection point with spermatic cords. About 15-20 days later, the scrotum, including testes, dropped off.

During the suckling period (12 weeks), kids with their dams were kept in a semi-opened pen with a yard. Beside suckling, kids were crept-fed, starting from the fifty week of age, on a ground grain mixture at an average rate of $100 \mathrm{~g} / \mathrm{head}$ daily to encourage high growth. The grain mixture consisted of $35 \%$ yellow corn, $35 \%$ barley and $30 \%$ soybean meal.

After weaning, kids were fed ad libitum on Egyptian clover (Trifolium alexandrinum) in winter and sorghum (Sorghum bicolor) or clover hay in the rest of the year according to their availability. At weaning time, each kid was supplemented daily with $200 \mathrm{~g}$ of the ground grain mixture, increased gradually to reach $400 \mathrm{~g}$ by sixth month of age. Afterwards, a daily allowance of $500 \mathrm{~g}$ pellet concentrate mixture plus $250 \mathrm{~g}$ barley was given to each kid till the end of experiment. The pellet mixture consisted of $42 \%$ cotton seed meal, $25 \%$ wheat bran, $22 \%$ yellow corn, $5 \%$ rice bran, $3 \%$ molasses, $2 \%$ limestone and $1 \%$ common salt. Kids had free access to water.

\section{B. Skin sampling and light microscopic examination:}

Entire and castrated kids had physical contact with does in estrus prior to slaughter for 14 days. Kids under the study were slaughtered at 16 months of age. Five areas of skin (parietal, shoulder, mid-side, coxal tuber and perianal), each of $1 \times 1 \mathrm{~cm}$, were marked immediately before slaughtering as shown in Fig. 1

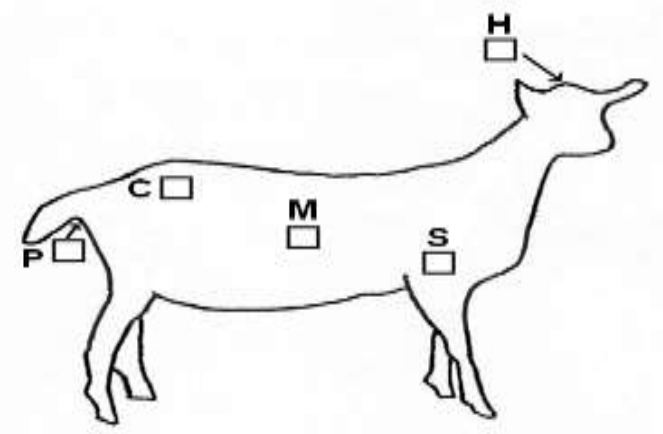

Fig 1: Body regions on the right side of goats from which skin samples Were taken: H, parietal (horn) region; S, shoulder; M, mid-side; $C$, region of coxal tuber and $P$, perianal region. 
The marked samples were removed from the skin of all nine animals just after slaughtering and directly fixed in 10\% formol saline for 24 hours, then washed thoroughly in running water and stored directly in $70 \%$ ethyl alcohol. Samples were trimmed to $5 \times 5 \mathrm{~mm}$ pieces, dehydrated in a series of ethyl alcohol grades $(80 \%, 90 \%$ and $100 \%)$. Afterwards, samples were cleared in xylene and impregnated in soft paraffin wax. By using rotary microtome sections of about 4-6 micrometers thick were obtained and stained with Harris hematoxylin and eosin, periodic acid Schiff (PAS) and Crossmon's trichome stains as outlined by Drury and Wallington (1980) and Bancroft and Gamble (2008). With the aid of light microscopy, the number of primary and secondary hair follicles as well as trio groups, sebaceous glands and sweat glands could be calculated per 20 randomly chosen cubic millimeters from which the mean could be determined. The diameters of external and internal root sheaths of 20 randomly chosen hair follicles both primary and secondary of each sample were measured by using the Image $\mathrm{J}$ analysis software program, Microsoft Company, with the aid of Canon system digital camera connected to light microscope using 10X objective lens. The thickness of epidermis and keratin layer alone was measured by the same system but using 40X objective lens. All the above mentioned measurements of image analysis program were calculated in pixels as suggested by Ansi (2004) and Cipa (2005).

\section{C-Statistical analysis:}

Data were analysed by least squares procedure of the General Linear Models Program of SAS (2004). The fixed models used was:

Where:

$$
Y_{i j k}=\mu+r_{i}+c_{j}+e_{i j k}
$$

$\mathrm{Y}_{\mathrm{ijk}}$ is the skin trait studied of the kid $\mathrm{k}$ for castration age $\mathrm{j}$ and body region $\mathrm{i}$, $\mu$ is the overall mean,

$r_{i}$ is the fixed effect of body region $(i=1,2, \ldots, 5 ; 1=$ parietal; $2=$ shoulder; $3=$ mid-side; $4=$ coxal tuber and $5=$ perianal $), c_{j}$ is the fixed effect of castration age $(j=1,2$ or $3 ; 1=$ entire kid, $2=$ castrated at 2 weeks of age and $3=$ castrated at 6 months of age),and $e_{\mathrm{ijk}}$ is a random error assumed to be normally and independently distributed.

It was not possible to detect the significance of interactions because of the limitation of data. Differences among means within each classification were tested using Duncan's New Multiple Range Test. Correlation coefficients among skin traits were calculated and tested.

\section{RESULTS AND DISCUSSION}

\section{A. Effect of body region:}

It appears from Table 1 that body region exerted a highly significant $(P<0.01)$ effect on all skin traits studied except, S/P ratio and thickness of epidermis and keratin layers. The effect of body region on $S / P$ ratio was statistically significant $(P<0.05)$. Whereas, no significant differences $(P>0.05)$ in thickness of epidermis and keratin layers due to body region effect were observed. 
Abdel-Moneim, A.Y. and Kh. M. Mazher

1

286 
Meanwhile, results in Table 1 reveal that parietal region had significantly $(P<0.05)$ the highest density of follicles $\left(55.8 / \mathrm{mm}^{2}\right)$ over other body regions. Similar finding was obtained by Wuliji et al. (2006) in Spanish goats. Whereas, the least density of follicles was found in mid-side region $\left(27.1 / \mathrm{mm}^{2}\right)$. Intermediate values of follicles density were obtained from perianal $\left(42.9 / \mathrm{mm}^{2}\right)$ and shoulder $\left(42.1 / \mathrm{mm}^{2}\right)$ regions. Furthermore, skin from parietal and shoulder regions contained significantly $(P<0.05)$ more trio groups than that of mid-side, coxal tuber and perianal regions. As well, number of primary follicles was significantly $(P<0.05)$ higher in parietal and perianal regions than that of shoulder, mid-side and coxal tuber regions .

It is striking that the ratio of secondary/primary follicles $(\mathrm{S} / \mathrm{P}$ ratio) is considered as a useful measure of secondary follicle population (Abdelsalam and Haider, 1993 and Wuliji et al., 2006 ). S/P ratio in parietal and shoulder regions was significantly $(P<0.05)$ lower than that in perianal region. Whereas, $S / P$ ratio in mid-side and coxal tuber regions did not significantly differ with other body regions studied.

Concerning diameter of follicles, it was observed (Table 1) that the internal and external root sheaths diameters of primary follicles were significantly $(P<0.05)$ lower in perianal region than those of other regions. However, the differences among means of the other four regions (parietal, shoulder, mid-side and coxal tuber) were not significant $(P>0.05)$. Additionally, the least internal and external diameters of secondary follicles were significantly $(P<0.05)$ found in perianal area compared with the other regions. Whereas, the highest internal and external diameters of secondary follicles were obtained from coxal tuber region. Intermediate estimates of internal and external diameters of secondary follicles were found in parietal, shoulder and mid-side regions .

It is of interest (Table 1) that sweat glands density was significantly $(P<0.05)$ higher in parietal $\left(14.8 / \mathrm{mm}^{2}\right)$ and perianal $\left(12.9 / \mathrm{mm}^{2}\right)$ regions than in shoulder $\left(5.7 / \mathrm{mm}^{2}\right)$, mid-side $\left(6.3 / \mathrm{mm}^{2}\right)$ and coxal tuber $\left(7.0 / \mathrm{mm}^{2}\right)$ regions. In this respect, perianal region had significantly $(P<0.05)$ the highest density of sebaceous glands $\left(36.6 / \mathrm{mm}^{2}\right)$. Whereas, parietal region ranked the second in respect to sebaceous glands density $\left(26.0 / \mathrm{mm}^{2}\right)$, followed by that of coxal tuber region $\left(21.2 / \mathrm{mm}^{2}\right)$. Whereas, the least density of sebaceous glands was found in mid-side region $\left(14.4 / \mathrm{mm}^{2}\right)$. Various investigators confirmed that skin glands of bucks are the major source of odor (Jenkinson et al., 1967; Ford, 1977; Dmi'el, 1986; Parmar et al., 1988; Chukwu and Ihemelandu, 1989 and Rekwot et al., 2001).

It is well established that parietal region (horn glands) of male Baladi goats had the highest follicles density, number of primary follicles and trio groups compared with other body regions. Furthermore, the highest density of sweat glands was found in parietal region of male goats. Moreover, the highest diameter of internal and external primary follicles was found in parietal region over other body regions studied. Hence, it could be deduced from the attained results that the major source of buck odor may be originated from the skin glands located in the parietal region. The attained results are in accordance with the findings of Jenkinson et al. (1967), Dmi'el (1986), Parmar et al. (1988), Chukwu and Ihemelandu (1989) and Van 
Lancker et al. (2005) working on different breeds of goats. Jenkinson et al. (1967) showed that the rutting odor of British Saanen buck originates in or on the skin of the head and neck. Parmar et al. (1988) using different breeds of Indian goats indicated that the major scent glands of male goats are located around the horn base. In the meantime, Chukwu and Ihemelandu (1989) working on Nigerian breeds of goats (West African dwarf goats and red Sokoto goats) found that sebaceous glands in the horn glands showed significantly larger cross-sectional areas than sebaceous glands elsewhere in the body. Furthermore, Van Lancker et al., (2005) reported that odor of Toggenburg buck was most apparent in the horn gland area. Contrarily, Schummer et al. (1981) attributed odor of buck to sub-caudal glands.

It is clear (Table 1) that the thickest epidermal layer was found in perianal region over other body regions. The significant difference was found between mean of epidermal layer thickness of perianal region and those of mid-side and coxal tuber. On the other side, no significant difference $(P>0.05)$ in the thickness of keratin layer due to body region was found.

Despite the perianal region had significantly $(P<0.05)$ less diameter of primary and secondary follicles, whether internal or external sheaths than other body regions, it was superior in density of sebaceous glands, thickness of epidermal layer and S/P ratio over other regions. This result may be attributed to that secondary follicles in perianal region were accompanied with sebaceous glands rather than secondary follicles in other body regions. Thus, the superiority of sebaceous glands in parietal region for producing buck odor goes hand to hand with that illustrated by Chukwu and Ihemelandu (1989) and Otberg et al. (2004). The authors showed that ducts of the sebaceous gland of the horn glands usually open into hair follicles but few ducts open on the surface of the skin, as recorded in our study.

\section{B. Effect of age at castration:}

Table 2 shows that castration age had significant effect on $S / P$ ratio $(P<0.05)$, trio groups $(P<0.05)$, internal diameter of secondary follicles $(P<0.05)$, sweat glands density $(P<0.01)$ and thickness of keratin layer $(P<0.05)$. Nevertheless, castration treatment did not exhibit a significant $(P>0.05)$ difference on follicles density and number of primary follicles, entire Baladi kids had higher follicles density and number of primary follicles than castrated kids, whether at 2-week or 6-month of age. In this context, entire kids had lower S/P ratio than castrated ones. The significant $(P<0.05)$ difference was found between entire kids and 6-month castrates. Meanwhile, Eppleston and Moore (1990) found that Australian Angora does had a greater S/P ratio than bucks. Furthermore, Abdelsalam and Haider (1993) showed that histological characters and measurements of skin of male Angora and Baladi goats were greater in males than in females. In the meantime, results in the same Table indicate that skin of entire kids had significantly $(P<0.05)$ higher trio groups than castrated kids at two weeks of age. No significant difference was obtained between trio groups of 6-month castrates and that of entire kids.

It is also appeared that diameters of internal and external sheaths of primary follicles were not affected by age of castration. Nevertheless, 
diameters of internal and external sheaths of primary follicles were slightly less in skin of entire kids than that of castrated ones. The same trend was observed for diameters of internal and external sheaths of secondary follicles. Whereas, the diameter of internal sheath of secondary follicles was significantly $(\mathrm{P}<0.05)$ less in entire kids than in castrated ones whatever the age of castration.

On the other hand, it is striking that skin of entire kids had higher density of sweat glands than that of castrated kids (Table 2). The significant difference was only found between entire kids and 2-week castrates. Though the difference in density of sebaceous glands due to castration age was insignificant $(P>0.05)$, the mean of sebaceous glands density of entire kids was higher than that of castrated ones. The obtained results are in harmony with those reported by Jenkinson et al. (1967), Chukwu and Ihemelandu (1989), Iwata et al. (2000), Van Lancker et al. (2005) and Kakuma et al. (2007). Jenkinson et al. (1967) found that male of Saanen goats had wider sweat glands in parietal area than the females or castrated males. Moreover, the authors showed that no significance $(P>0.05)$ in diameter of sweat glands was found between females and castrates. In West African dwarf goats and red Sokoto goats, sebaceous glands in the horn glands were significantly $(P<0.05)$ larger in males than in females (Chukwu and Ihemelandu, 1989). In the meantime, Van Lancker et al. (2005) found that in castrated Toggenburg bucks, the average glandular (cornual, sub- caudal, mental and preputial) size tended to be little smaller than in the intact males. The authors indicated that complete absence of buck odor was observed in castrated bucks. In this context, Sugiyama et al. (1981) found that sebum secreted from sebaceous glands of bucks contained 4-ethyl-branched fatty acids compared with components of sebum from does. This secretion is controlled by sexhormones. Meanwhile, Smith et al. (1984) found that 4-ethyloctanoic acid showed a strong goat's odor at low concentrations. Moreover, Iwata et al. (2000) and Kakuma et al. (2007) demonstrated that androgen is capable of inducing primer male pheromone activity in castrated male and female goats. ESGPIP (2008) reported that meat from castrated males has less "goat smell" or tainted odor than that from intact bucks.

It was noticed (Table 2) that epidermal layer thickness was not significantly affected by age of castration. Nevertheless, the thickness of keratin layer was significantly $(P<0.05)$ higher in entire kids than in 2-week castrated ones. Keratin layer thickness did not significantly differ between entire kids and 6-month castrates.

It is interesting to show that comparing with entire kids, castration at 2week of age had much more pronounced effect on skin glands and follicles rather than castration at 6-month of age. Hence, it seems preferable to castrate male Baladi kids at early ages to reduce buck odor.

\section{C- The relationships among skin traits:}

Table 3 shows that follicles density was positively and highly significant $(P<0.01)$ correlated with each of number of primary follicles, trio groups, sweat glands density and sebaceous glands density. Thus, it could be deduced that the increase of follicles density especially primary follicles is 
accompanied with increasing the secretion of sebaceous and sweat glands. Whereas, a negative and significant $(P<0.05)$ correlation coefficient was obtained between follicles density and S/P ratio. Furthermore, the correlation coefficient between $S / P$ ratio and trio groups was negative and highly significant $(P<0.01)$. These results coincided with Wuliji et al. (2006) who found that the correlation coefficient between number of primary follicles and $S / P$ ratio in skin of Spanish goats was negative and highly significant $(r=-$ $0.48, P<0.01$ ). Hence, $S / P$ ratio in skin of parietal region was lower than that of mid-side, coxal tuber and perianal regions. In the meantime, positive and significant correlations were found between number of primary follicles and each of trio groups $(P<0.05)$, density of sweat and sebaceous glands $(P<0.01)$ and thickness of epidermal layer $(P<0.05)$. These findings may be explained as the higher follicles density, number of primary follicles and trio groups as well as the lower S/P ratio in the entire males might be responsible for their odor compared with the castrated ones. Additionally, positive and significant correlation coefficients were obtained between trio groups and each of internal diameter of primary follicle sheaths $(P<0.01)$, external diameter of primary follicle sheaths $(P<0.05)$ and thickness of keratin layer $(\mathrm{P}<0.05)$.

On the other hand, Table 3 indicates also that the correlation coefficients among diameters of internal and external primary and secondary follicles were positive and highly significant $(P<0.01)$. Whereas, sebaceous glands density was negatively and significantly correlated with each of internal and external root sheaths diameters of primary follicles $(P<0.01)$ and internal and external root sheaths diameters of secondary follicles $(P<0.05)$. Thus, the increase in sebaceous glands density was accompanied with decreasing internal and external sheaths diameters of primary and secondary follicles. Hence, skin of entire kids had less diameters of primary and secondary follicles, whether internal or external, than skin of castrated ones. Similar trend was observed by Wuliji et al. (2006) who found that number of primary follicles in Spanish goats was negatively and significantly ( $P<0.01)$ correlated with primary follicle diameter $(r=-0.42)$ and secondary follicle diameter $(r=-0.33)$.

It could be observed (Table 3 ) that sweat glands density was positively and highly significant $(P<0.01)$ correlated with sebaceous glands density. Meanwhile, a positive and highly significant $(P<0.01)$ correlation coefficient between sebaceous glands density and thickness of epidermal layer was obtained. Moreover, the correlation coefficient between thickness of epidermal layer and thickness of keratin layer was positive and highly significant $(\mathrm{P}<0.01)$.

It should be pointed out that skin of entire Baladi kids exposed to does in estrus had higher trio groups and density of sweat and sebaceous glands and less S/P ratio than skin of castrated kids. Despite, the buck odor plays a primary role in inducing ovulation of does (Delgadillo et al., 2006), it hurts goat products if it is not properly controlled (Parmar et al., 1988).Thus, good hygiene practices must be applied to minimize buck odor. It could be deduced from the aforementioned discussion that castration of kids is a useful tool to reduce the odor of goat smell in goat products. 
J. Animal and Poultry Production, Mansoura University, Vol. 1 (7), July 2010

$2-3$ 


\section{Abdel-Moneim, A.Y. and Kh. M. Mazher}

\section{Histological findings:}

1. Odor or buck glands:

The odor glands of the entire kids in the parietal (horn base) region and to some extent the perianal region appeared highly modified enlarged sebaceous gland occupying the majority of the dermis (Fig. 2). It consisted of several large lobules of holocrine type of glands either associated with hair follicles or open independently onto the skin. The finding obtained herein is in agreement with the finding of Van Lancker et al. (2005) who showed that the sebaceous gland consisted of two or more lobes lied on either sides of the primary and some few secondary follicles. Each lobe had a very short duct opening in the hair follicle. In this context, Whiting (2000) mentioned that the primary follicle was characterized by the presence of three accessory structures, sebaceous and sweat glands as well as the pili muscle. The secondary follicle was not accompanied by either sweat gland or pili muscle and rarely possessed sebaceous gland. It was observed (Fig. 3) that the gland lobules were supported by bundles of collagen fibers carrying blood vessels and nerves. Each lobule was formed of mitotically active basal cuboidal to columnar cells with basophilic cytoplasm and central large polyhedral ones with vacuolated cytoplasm (Fig. 4). The basal basophilic cells showed moderate Periodic Acid Schiff (PAS) reaction while the central ones reacted very weak or may be negative (Fig. 5). In the castrated kids especially those castrated at 2 weeks of age, the odor gland appeared as isolated smaller lobules containing less active cells with pyknotic nuclei and less vacuolated cytoplasm. Also there was a marked proliferation of connective tissue (Fig. 6). The glands in the other body regions in entire kids resemble those of castrated ones.

\section{Hair follicles:}

The primary hair follicles in most regions of the entire kids appeared large, thick and more rigid. Each follicle consisted of an external root sheath, an internal root sheath and a connective tissue sheath. The external sheath was formed of terminative cuboidal to polyhedral cells with basophilic cytoplasm while the internal sheath appeared more cornified formed of cuticular cells (Fig. 7). In the castrated kids especially the 2-weeks castrates, the hair follicles became narrower, shorter and smaller with a marked reduction of the diameters of both external and internal sheaths (Fig. 8). The results concerning the secondary follicles ran in the same way of primary ones.

\section{Epidermis of skin:}

The epidermis of skin covering the studied regions in the entire kids appeared thick and more cornified. The epidermis was formed of several layers of epithelial cells covered by tough non living acidophilic keratin layer (Fig. 9). In the castrated kids the thickness of epidermis became slightly reduced while that of the keratin layer was greatly reduced leaving a very thin keratin layer (Fig. 10).

\section{4.) Sweat glands:}

Regarding the sweat glands in all studied regions, they were formed of several alveoli lined by simple and/or stratified columnar cells in addition to many ducts carrying the sweat onto the surface of skin (Fig. 11). There was 
not any structural difference between castrated and entire kids. Similar findings were reported by Chukwu and Ihemelandu (1989) and Van Lancker et al.(2005) who reported that the sweat gland consisted of a convoluted saccular body and open freely on the epidermis.

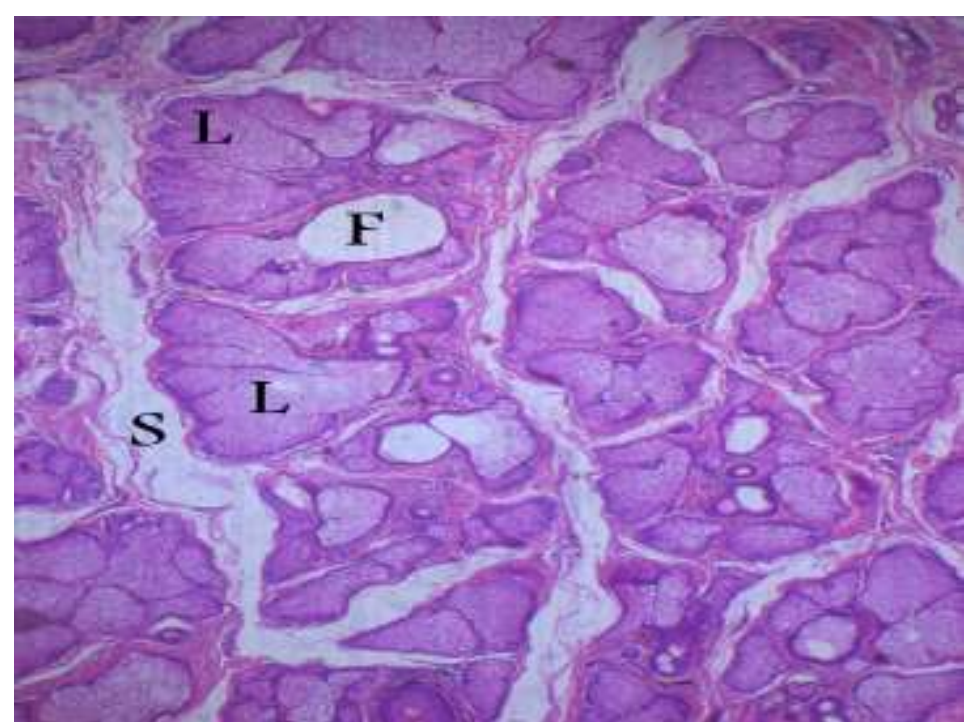

Fig. 2: A photomicrograph of the odor gland of entire kid in the parietal region showing several lobules of the gland (L) surrounded by CT (S). Note hair follicle (F). H\&E stain, X200

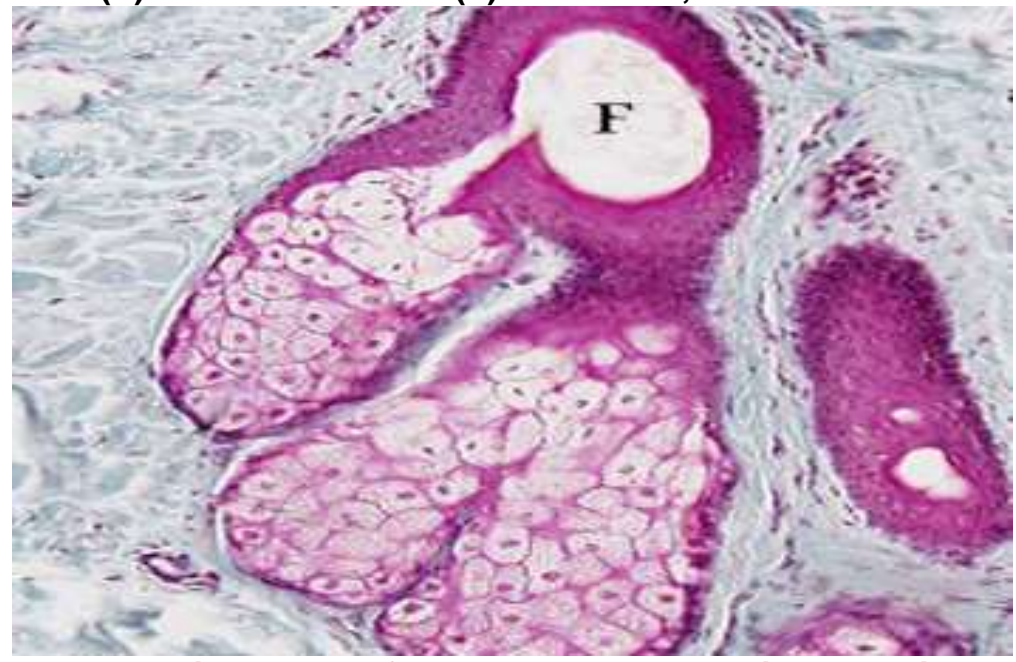

Fig. 3: A photomicrograph of the sebaceous gland in the parietal region of entire kid showing highly active large secretory lobules supported by CT carrying blood vessels. Note the gland open into hair follicle (F). crossmon's tricrome stain, X400 


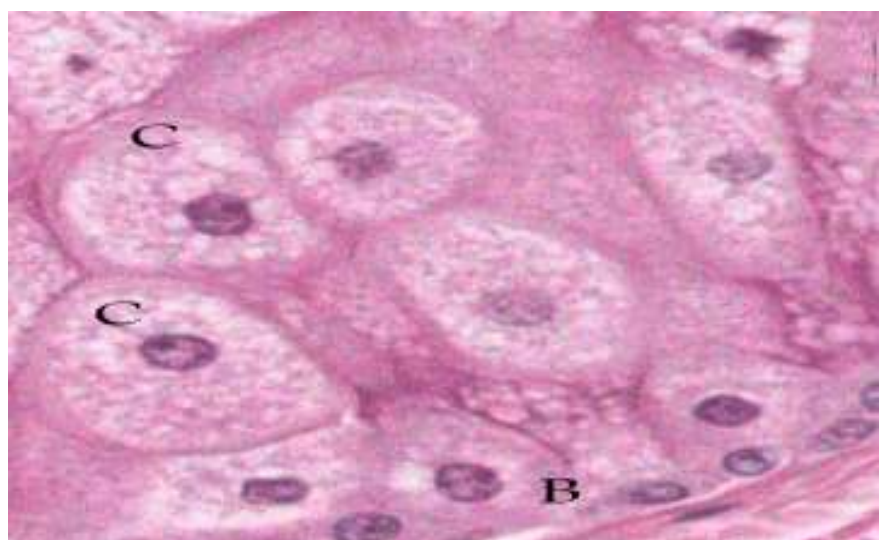

Fig. 4: A higher magnification of the odor gland of the parietal region of entire kid showing basal cells (B) and central cells with vacuolated cytoplasm (C). H\&E stain, X1000

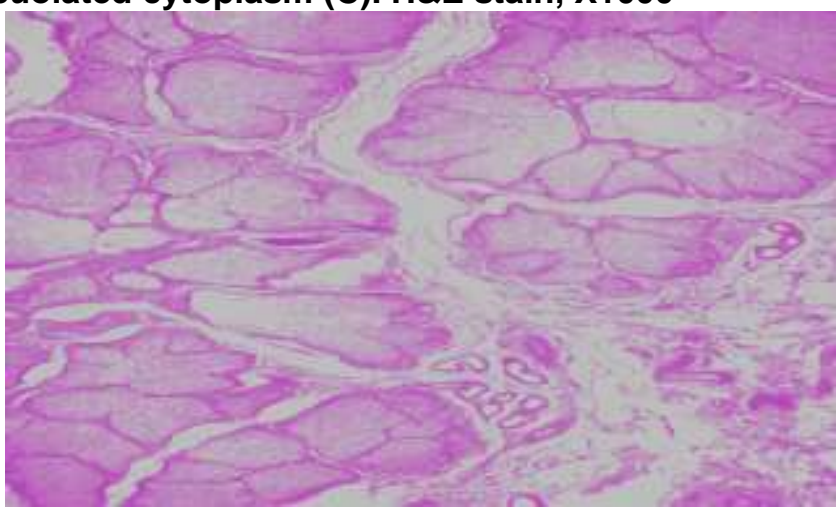

Fig. 5: A photomicrograph of the buck parietal gland of the entire kid showing moderate PAS reaction in the basal cells and weak reaction in the central ones. PAS technique, X400

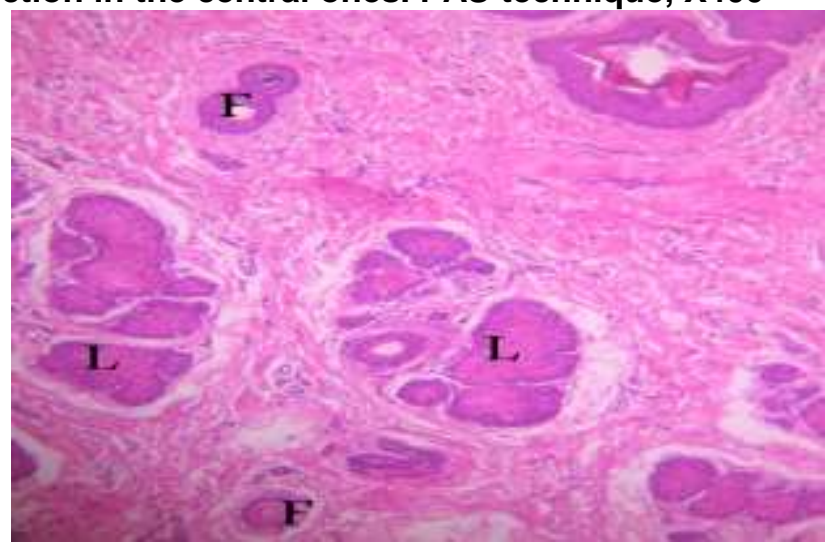

Fig. 6: A photomicrograph of the parietal gland of 2-week castrated kid showing small isolated less active lobules. Note the hair follicles became smaller and thinner. H\&E stain, X100 


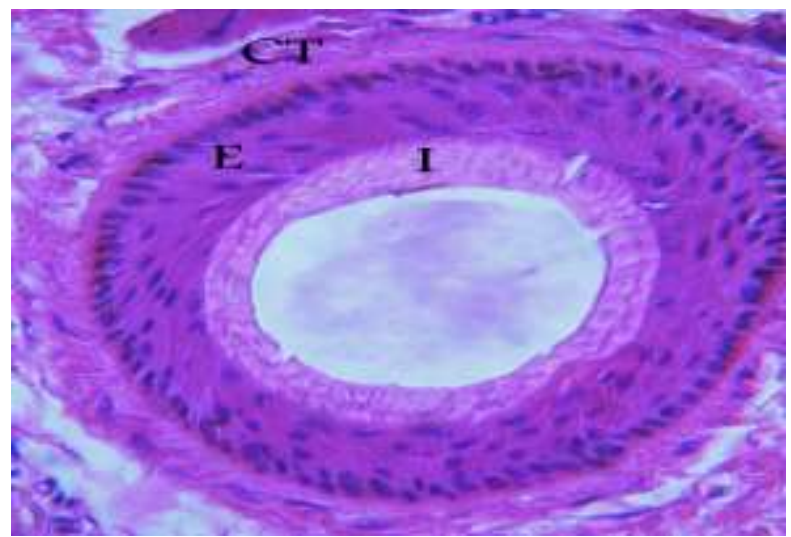

Fig. 7: A photomicrograph of the hair follicle of entire kid showing large thick follicle formed of external sheath $(E)$, internal sheath $(I)$ and CT sheath (CT).H\&E stain, X400

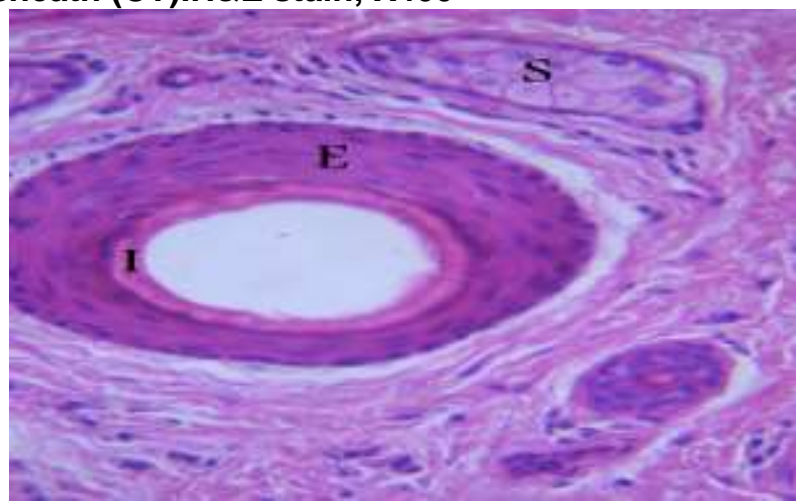

Fig. 8: A photomicrograph of the hair follicle of 2 -week castrated kid showing that both external $(E)$ and internal (I) sheaths became thinner. H\&E stain, X400.

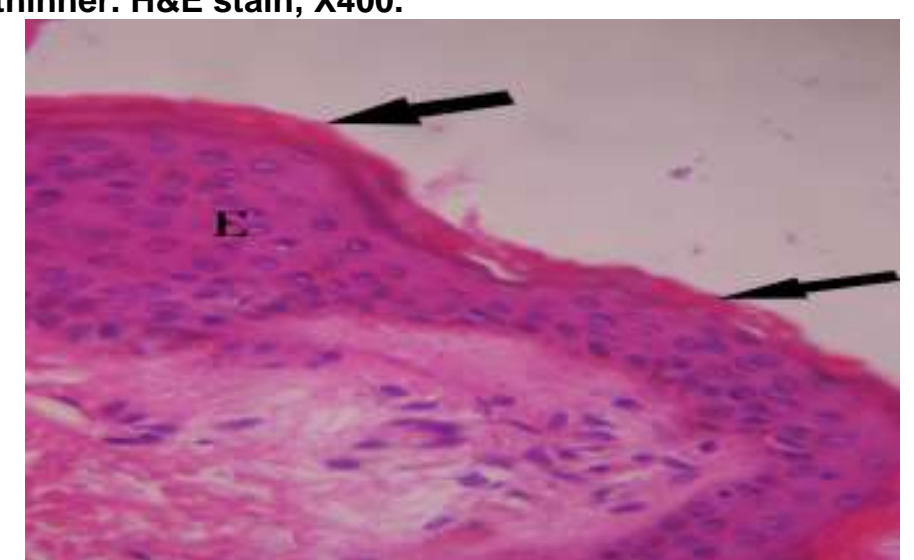

Fig. 9: A section through the skin of the entire kid showing thick epidermis (E) and keratin layer (arrow). H\&E stain, X1000 


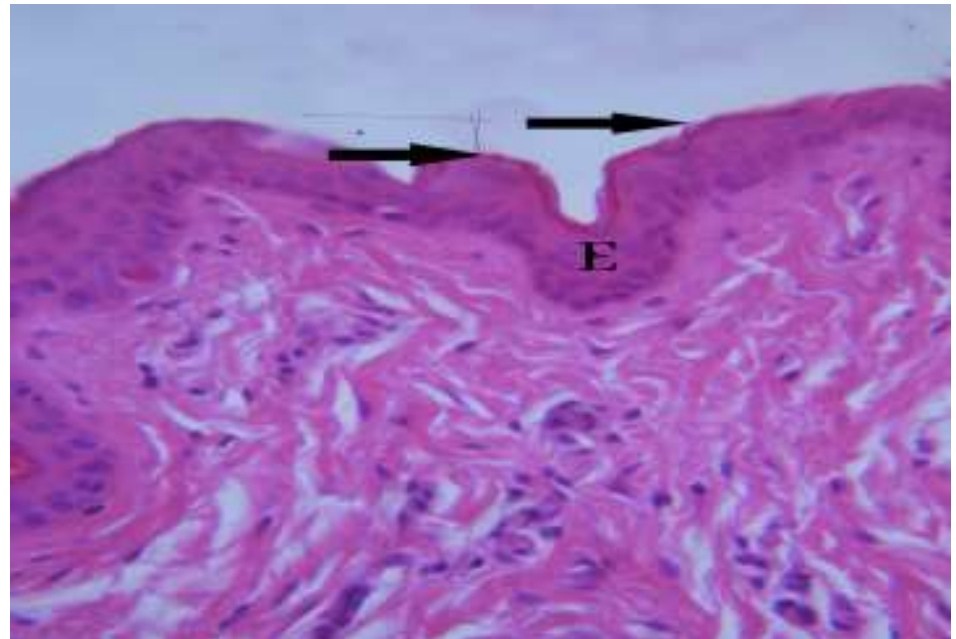

Fig. 10: A section in the skin of 2 - week castrated kid showing thin epidermis (E) and keratin layers (arrow). H\&E stain, X1000

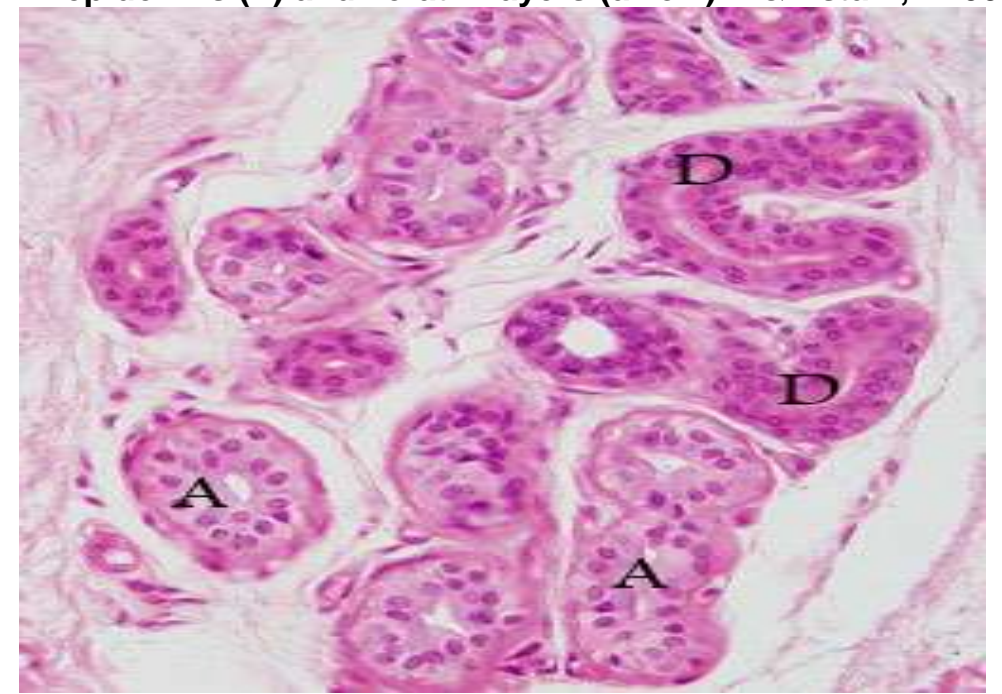

Fig. 11: A photomicrograph of the skin of entire kid showing well developed sweat gland formed of secretory alveoli $(A)$ and excretory duct (D)

\section{Conclusion}

Sweat and sebaceous glands in parietal region (horn glands) of Baladi bucks are the major source of buck odor. Castration plays an important role to minimize goat odor of milk and meat. It may be recommended to castrate male kids at early age of life (at the age of two weeks or may be earlier). 


\section{REFERENCES}

Abdelsalam, M. M. and A. I. Haider (1993). Physical and histological properties of sheep and goat skins. Alex. J. Agric. Res., 38 (2): 117138.

Ansi, T. (2004). Photography, Digital Still Cameras and Guidelines for Reporting Pixel - Related Specifications.

Bancroft, J. and A. Gamble (2008). Theory and Practice of Histological Techniques. $6^{\text {th }}$ Ed., Churchill-Livingstone, Edinburgh, London, Melbourne, New York

Chukwu, D. O. and E.C. Ihemelandu (1989). Morphometric studies on horn glands of Nigerian breeds of goat. Small Rumin. Res., 2: $367-374$.

Cipa, D. (2005). Guideline for Noting Digital Camera Specifications in Catalogs " The term 'Resolution' shall not be used for the number of recorded pixels".

Delgadillo, J. A.; J. A. Flores; F. G. Véliz; G. Duarte; J. Vielma; H. Hernandez and I. G. Fernandez ( 2006 ). Importance of the signals provided by the buck for the success of the male effect in goats. Reprod. Nutr. Dev., 46: $391-400$.

Dmi'el, R. (1986). Selective sweat secretion and panting modulation in dehydrated goats. Journal of Thermal Biology, 11: 157 - 159.

Drury R.A. and E.A. Wallington (1980): Carleton's Histological Technique. $4^{\text {th }}$ Ed. Oxford Univ. Press. London, New York and Toronto.

Eppleston, J. and N. W. Moore (1990). Fleece and skin characteristics of selected Australian Angora goats. Small Rumin. Res., 3 : 397 - 402.

ESGPIP ( 2008 ). Sheep and Goat Production Handbook for Ethiopia. Alemu Yami and R. C. Merkel ( eds. ). 350 pp.

Ford, R. S. (1977). How to deodorise bucks. Dairy Goat Journal, $55: 31-32$.

Iwata, E.; Y. Wakabayashi; Y. Kakuma; T. Kikusui; Y. Takeuchi and Y. Mori (2000). Testosterone-dependent primer pheromone production in the sebaceous gland of male goat. Biol. Reprod., 62: $806-810$.

Jenkinson, Mc. E. D.; P. S. Blackburn and R. Proudfoot ( 1967 ). Seasonal changes in the skin glands of the goat. Br. Vet. J. 123, $541-549$.

Kakuma, Y.; T. Ichimaru; T. Yonezawa; Y. Momozawa; C. Hashizume; E. Iwata; T. Kikusui; Y. Takeuchi; S. Ohkura; H. Okamura and Y. Mori (2007). Androgen induces production of male effect pheromone in female goats. J. Reprod. Dev., $53: 829-834$.

Otberg, N.; H. Richter; H. Schaefer; U. Blume-Peytavi; W. Sterry and J. Lademann (2004). Variations of hair follicle size and distribution in different body sites. J. Invest. Dermatol.; $122: 14-19$.

Parmar, M. L.; R. D. Sinha; G. Prasad and J. Prasad ( 1988 ). Histochemical studies on hair follicles and sebaceous and sweat glands in goat. Indian J. Anim. Sci., 58 ( 7 ) : $789-791$.

Rekwot, P. I.; D. Ogwu; E. O. Oyedipe and V. O. Sekoni ( 2001 ). The role of pheromones and biostimulation in animal reproduction. Anim. Reprod. Sci., $65: 157-170$. 
SAS (2004). SAS User's Guide: Statistics. Version 9.1. SAS Inst. Inc., Cary, NC., USA.

Schummer, A.; H. Wilkens; B. Vollmerhaus and K. H. Habermehl (1981). Skin and cutaneous organs. Specialized structures of the skin . In: R. Nickel; A. Schummer and E. Seiferle (Eds.). The anatomy of the domestic animals, vol. III. Verlag Paul Parey, Berlin und Hamburg, pp. 461 469.

Smith, P. W.; O. W. Parks and D. P. Schwartz (1984). Characterization of male goat odors: 6 - trans nonenal. J. Dairy Sci., 67 ( 4 ) : 794 - 801.

Sugiyama, T.; H. Sasada; J. Masaki and K. Yamashita (1981). Unusual fatty acids with specific odor from mature male goat. Agricultural and Biological Chemistry, $45: 2655-2658$.

Van Lancker, S.; W. Van Den Broeck and P. Simoens (2005). Morphology of caprine skin glands involved in buck odour production. The Veterinary Journal, 170: $351-358$.

Whiting, D. A. (2000). Histology of normal hair. In: Hordinsky M.K.; M.E. Sawaya and R. K. Scher, (eds) Atlas of Hair and Nail. Philadelphia / London/Toronto/Montreal/Sydney/Tokyo/Edinburgh:Churchill Livingstone. p 9-18.

Wuliji, T.; A. Litherland; A. L. Goetsch; T. Sahlu; R. Puchala; L. J. Dawson and T. Gipson (2006). Evaluation of melatonin and bromocryptine administration in Spanish goats. III. Effects on hair follicle activity, density and relationships between follicle characteristics. Small Rumin. Res., $66: 11-21$.

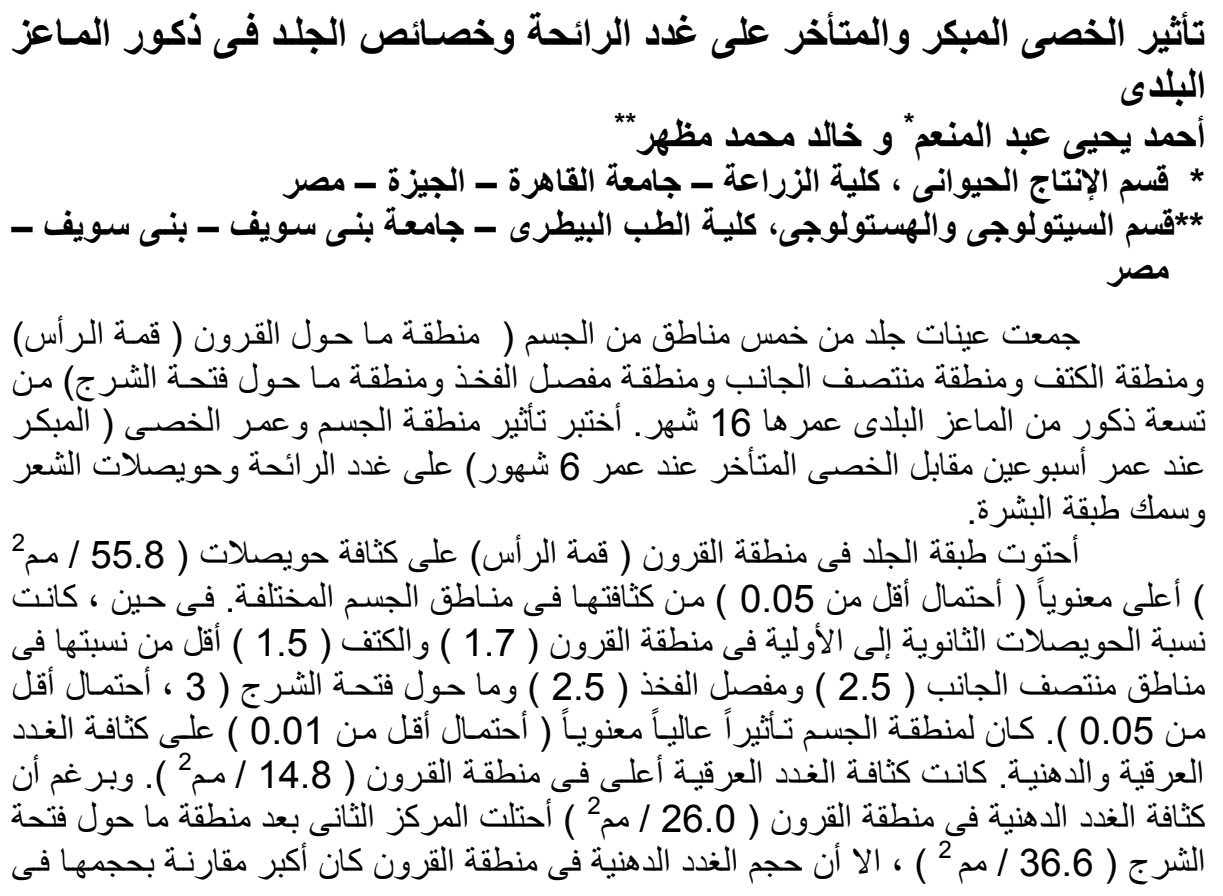




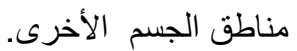

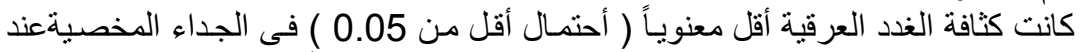

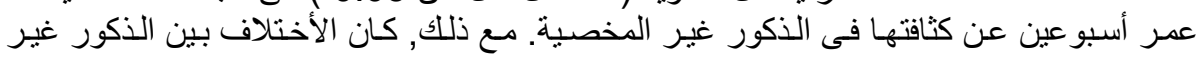

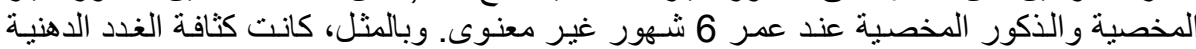

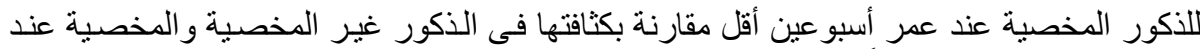

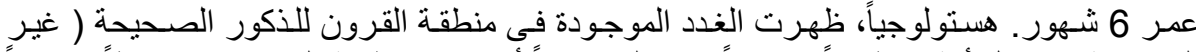

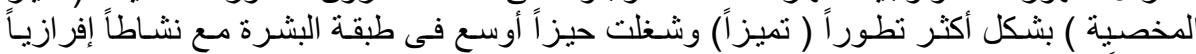

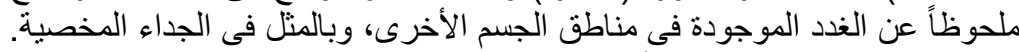

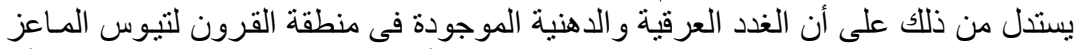

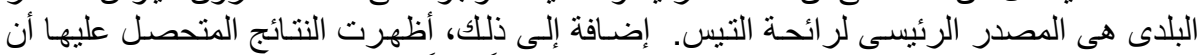
خصى الجداء عند عمر مبكر ( عمر أسبوعين ) يلعب دوراً هاماً فى خفض الرف رائحة الذكور.

كلية الزراعة - جامعة المنصورة

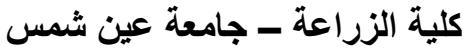

قام بتحكيم البحث

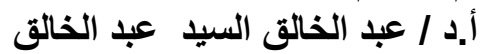

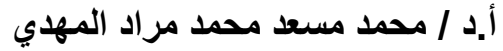


Table (1): Least squares means $(\bar{X})$ and standard errors (SE) of skin follicles and glands characteristics in male Baladi goats according to body region.

\begin{tabular}{|c|c|c|c|c|c|c|c|c|c|c|c|c|c|c|c|c|}
\hline \multirow{3}{*}{ Skin traits } & \multicolumn{15}{|c|}{ Body region } & \multirow{3}{*}{$\frac{\dot{0}}{\dot{\omega}}$} \\
\hline & \multicolumn{3}{|c|}{ Parietal } & \multicolumn{3}{|c|}{ Shoulder } & \multicolumn{3}{|c|}{ Mid-side } & \multicolumn{3}{|c|}{ Coxal tuber } & \multicolumn{3}{|c|}{ Perianal } & \\
\hline & $\mathbf{N}$ & $\overline{\mathbf{X}}$ & SE & $\mathbf{N}$ & $\overline{\mathbf{X}}$ & SE & $\mathbf{N}$ & $\overline{\mathbf{X}}$ & SE & $\mathbf{N}$ & $\overline{\mathbf{X}}$ & SE & $\mathbf{N}$ & $\overline{\mathbf{X}}$ & SE & \\
\hline (1) Follicles density $\left(1 \mathrm{~mm}^{2}\right)$ & 9 & $55.8^{a}$ & 3.7 & 9 & $42.1^{\mathrm{b}}$ & 3.7 & 9 & $27.1^{\mathrm{c}}$ & 3.7 & 9 & $34.1^{\mathrm{bc}}$ & 3.7 & 9 & $42.9^{b}$ & 3.7 & ** \\
\hline (2) Number of primary follicles $\left(1 \mathrm{~mm}^{2}\right)$ & 9 & $33.9^{\mathrm{a}}$ & 2.5 & 9 & $24.1^{\mathrm{b}}$ & 2.5 & 9 & $17.2^{b}$ & 2.5 & 9 & $23.2^{\mathrm{b}}$ & 2.5 & 9 & $31.8^{\mathrm{a}}$ & 2.5 & ** \\
\hline (3) $S / P$ ratio & 9 & $1.7^{\mathrm{b}}$ & 0.3 & 9 & $1.5^{\mathrm{b}}$ & 0.3 & 9 & $2.5^{\mathrm{ab}}$ & 0.3 & 9 & $2.5^{\mathrm{ab}}$ & 0.3 & 9 & $3.0^{\mathrm{a}}$ & 0.3 & * \\
\hline (4) Trio groups $\left(1 \mathrm{~mm}^{2}\right)$ & 9 & $8.7^{\mathrm{a}}$ & 1.0 & 9 & $7.8^{\mathrm{a}}$ & 1.0 & 9 & $4.9^{b}$ & 1.0 & 9 & $4.6^{b}$ & 1.0 & 9 & $4.0^{b}$ & 1.0 & ** \\
\hline (5) Internal diameter of PF (pixels) & 9 & $194.6^{\mathrm{a}}$ & 12.0 & 9 & $175.2^{\mathrm{a}}$ & 12.0 & 9 & $175.2^{a}$ & 12.0 & 9 & $178.0^{\mathrm{a}}$ & 12.0 & 9 & $46.9^{b}$ & 12.0 & ** \\
\hline (6) External diameter of PF (pixels) & 9 & $277.6^{\mathrm{a}}$ & 15.0 & 9 & $242.3^{\mathrm{a}}$ & 15.0 & 9 & $257.2^{\mathrm{a}}$ & 15.0 & 9 & $273.3^{\mathrm{a}}$ & 15.0 & 9 & $110.3^{b}$ & 15.0 & ** \\
\hline (7) Internal diameter of SF (pixels) & 9 & $43.8^{b}$ & 5.2 & 9 & $42.9^{b}$ & 5.2 & 9 & $44.2^{b}$ & 5.2 & 9 & $81.6^{\mathrm{a}}$ & 5.2 & 9 & $14.9^{c}$ & 5.2 & ** \\
\hline (8) External diameter of SF (pixels) & 9 & $80.8^{\mathrm{b}}$ & 4.8 & 9 & $82.4^{\mathrm{b}}$ & 4.8 & 9 & $68.2^{b}$ & 4.8 & 9 & $138.4^{\mathrm{a}}$ & 4.8 & 9 & $29.7^{c}$ & 4.8 & ** \\
\hline (9) Sweat glands density $\left(1 \mathrm{~mm}^{2}\right)$ & 9 & $14.8^{\mathrm{a}}$ & 1.0 & 9 & $5.7^{b}$ & 1.0 & 9 & $6.3^{b}$ & 1.0 & 9 & $7.0^{b}$ & 1.0 & 9 & $12.9^{\mathrm{a}}$ & 1.0 & ** \\
\hline (10) Sebaceous glands density $\left(1 \mathrm{~mm}^{2}\right)$ & 9 & $26.0^{b}$ & 2.6 & 9 & $18.1^{\mathrm{bc}}$ & 2.6 & 9 & $14.4^{\mathrm{c}}$ & 2.6 & 9 & $21.2^{\mathrm{bc}}$ & 2.6 & 9 & $36.6^{\mathrm{a}}$ & 2.6 & ** \\
\hline (11) Thickness of epidermis (pixels) & 9 & $409.8^{a b}$ & 27.2 & 9 & $426.9^{a}$ & 27.2 & 9 & $381.2^{b}$ & 27.2 & 9 & $376.4^{b}$ & 27.2 & 9 & $473.1^{\mathrm{a}}$ & 27.2 & NS \\
\hline (12) Thickness of keratin layer (pixels) & 9 & $92.0^{\mathrm{a}}$ & 5.5 & 9 & $105.9^{\mathrm{a}}$ & 5.5 & 9 & $95.6^{\mathrm{a}}$ & 5.5 & 9 & $95.6^{\mathrm{a}}$ & 5.5 & 9 & $98.3^{a}$ & 5.5 & NS \\
\hline
\end{tabular}

Means in a row with different superscripts (a,bandc) are significantly $(P<0.05)$ different.

PF: Primary follicles,

SF: Secondary follicles

Sig.: Significance,

SF: Secondary follicle

* $P<0.05$,

${ }^{* *} \mathrm{P}<0.01$ 
Table (2): Least squares means $(\bar{X})$ and standard errors (SE) of skin follicles and glands characteristics in male Baladi goats according to age at castration.

\begin{tabular}{|c|c|c|c|c|c|c|c|c|c|c|}
\hline \multirow{3}{*}{ Skin traits } & \multicolumn{9}{|c|}{ Age at castration } & \multirow{3}{*}{ Sig. } \\
\hline & \multicolumn{3}{|c|}{ Entire kids } & \multicolumn{3}{|c|}{ Castrated at 2 weeks } & \multicolumn{3}{|c|}{ Castrated at 6 weeks } & \\
\hline & $\mathbf{N}$ & $\overline{\mathbf{X}}$ & SE & $\mathbf{N}$ & $\overline{\mathbf{X}}$ & SE & $\mathbf{N}$ & $\overline{\mathbf{X}}$ & SE & \\
\hline (1) Follicles density $\left(1 \mathrm{~mm}^{2}\right)$ & 15 & $43.8^{\mathrm{a}}$ & 2.9 & 15 & $39.1^{\mathrm{a}}$ & 2.9 & 15 & $38.3^{\mathrm{a}}$ & 2.9 & NS \\
\hline (2) Number of primary follicles $\left(1 \mathrm{~mm}^{2}\right)$ & 15 & $28.8^{\mathrm{a}}$ & 1.9 & 15 & $25.4^{\mathrm{a}}$ & 1.9 & 15 & $23.9^{\mathrm{a}}$ & 1.9 & NS \\
\hline (3) $S / P$ ratio & 15 & $1.7^{\mathrm{b}}$ & 0.3 & 15 & $2.2^{\mathrm{ab}}$ & 0.3 & 15 & $2.8^{\mathrm{a}}$ & 0.3 & * \\
\hline (4) Trio groups $\left(1 \mathrm{~mm}^{2}\right)$ & 15 & $7.3^{\mathrm{a}}$ & 0.8 & 15 & $4.3^{b}$ & 0.8 & 15 & $6.3^{\mathrm{ab}}$ & 0.8 & * \\
\hline (5) Internal diameter of PF (pixels) & 15 & $147.3^{\mathrm{a}}$ & 9.3 & 15 & $163.8^{\mathrm{a}}$ & 9.3 & 15 & $150.9^{\mathrm{a}}$ & 9.3 & NS \\
\hline (6) External diameter of PF (pixels) & 15 & $227.1^{\mathrm{a}}$ & 11.6 & 15 & $239.1^{\mathrm{a}}$ & 11.6 & 15 & $230.2^{\mathrm{a}}$ & 11.6 & NS \\
\hline (7) Internal diameter of SF (pixels) & 15 & $36.7^{\mathrm{b}}$ & 4.0 & 15 & $48.7^{\mathrm{a}}$ & 4.0 & 15 & $51.0^{\mathrm{a}}$ & 4.0 & $*$ \\
\hline (8) External diameter of SF (pixels) & 15 & $74.0^{\mathrm{a}}$ & 3.7 & 15 & $82.0^{\mathrm{a}}$ & 3.7 & 15 & $83.7^{\mathrm{a}}$ & 3.7 & NS \\
\hline (9) Sweat glands density $\left(1 \mathrm{~mm}^{2}\right)$ & 15 & $11.3^{\mathrm{a}}$ & 0.8 & 15 & $7.4^{\mathrm{b}}$ & 0.8 & 15 & $9.3^{\mathrm{ab}}$ & 0.8 & ** \\
\hline (10) Sebaceous glands density $\left(1 \mathrm{~mm}^{2}\right)$ & 15 & $26.3^{\mathrm{a}}$ & 2.0 & 15 & $21.7^{\mathrm{a}}$ & 2.0 & 15 & $21.9^{\mathrm{a}}$ & 2.0 & NS \\
\hline (11) Thickness of epidermis (pixels) & 15 & $424.5^{\mathrm{a}}$ & 21.1 & 15 & $402.1^{\mathrm{a}}$ & 21.1 & 15 & $413.8^{\mathrm{a}}$ & 21.1 & NS \\
\hline (12) Thickness of keratin layer (pixels) & 15 & $104.2^{\mathrm{a}}$ & 4.3 & 15 & $85.8^{\mathrm{b}}$ & 4.3 & 15 & $102.4^{\mathrm{a}}$ & 4.3 & 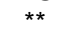 \\
\hline
\end{tabular}

Means in a row with different superscripts (aand b) are significantly $(P<0.05)$ different.

PF: Primary follicles, $\quad$ SF: Secondary follicles Sig.: Significance,

NS: Not significant, $\quad{ }^{*} P<0.05, \quad{ }^{* *} P<0.01$

Table (3): Correlation matrix among skin characteristics of male Baladi goats

\begin{tabular}{|c|c|c|c|c|c|c|c|c|c|c|c|}
\hline Skin characteristics & (1) & (2) & (3) & (4) & (5) & (6) & (7) & (8) & (9) & (10) & (11) \\
\hline (1) Follicles density & & & & & & & & & & & \\
\hline $\begin{array}{l}\text { (2) Number of primary follicles } \\
\text { (3) S/P ratio }\end{array}$ & $\begin{array}{l}0.91^{* *} \\
-0.37^{\star}\end{array}$ & -0.02 & & & & & & & & & \\
\hline (4) Trio groups & $0.58^{* *}$ & $0.35^{\star}$ & $-0.49^{* *}$ & & & & & & & & \\
\hline (5) Internal diameter of PF & -0.00 & -0.20 & -0.29 & $0.39^{* *}$ & & & & & & & \\
\hline (6) External diameter of PF & 0.01 & -0.16 & -0.21 & $0.32^{*}$ & $0.93^{\star *}$ & & & & & & \\
\hline (7) Internal diameter of SF & -0.20 & -0.18 & 0.17 & 0.09 & $0.62^{\star \star}$ & $0.67^{\star \star}$ & & & & & \\
\hline (8) External diameter of SF & -0.09 & -0.14 & -0.05 & 0.14 & $0.63^{* *}$ & $0.69^{* *}$ & $0.91^{\star *}$ & & & & \\
\hline (9) Sweat glands density & $0.63^{\star \star}$ & $0.75^{\star \star}$ & 0.13 & 0.16 & -0.23 & -0.22 & -0.23 & -0.29 & & & \\
\hline (10) Sebaceous glands density & $0.68^{\star \star}$ & $0.83^{\star *}$ & 0.10 & 0.03 & $-0.47^{\star \star}$ & $-0.40^{\star *}$ & $-0.32^{*}$ & $-0.32^{\star}$ & $0.68^{\star \star}$ & & \\
\hline (11) Thickness of epidermis & 0.23 & $0.31^{*}$ & 0.12 & 0.03 & -0.14 & -0.15 & -0.16 & -0.19 & 0.16 & $0.38^{* *}$ & \\
\hline (12) Thickness of keratin layer & 0.06 & 0.08 & 0.06 & $0.35^{\star}$ & 0.09 & 0.03 & 0.14 & 0.14 & -0.08 & -0.05 & $0.52^{\star \star}$ \\
\hline
\end{tabular}


Abdel-Moneim, A.Y. and Kh. M. Mazher 